\title{
Eğitimde akreditasyonun önemi
}

\section{The importance of accreditation in education}

\author{
Volkan Öztuna \\ Mersin Üniversitesi Tıp Fakültesi, Ortopedi ve Travmatoloji Anabilim Dalı, Mersin
}

\begin{abstract}
$\Lambda$
kreditasyon terimi, kurumların, hizmetlerin ve faaliyetlerin belirli yetkinlik ölçütlerine uygun olduğunu güvence altına almaya yönelik bir sistemi tanımlar. Bu sistem evrensel değerler üzerinden tanımlanmış ve devamlı güncellenen standardizasyon ölçütleri üzerinden hareket eder. İki tür akreditasyondan bahsedilebilir. Birincisi kurum akreditasyonudur ki eğitim kurumunun idari, mali ve akademik altyapısını değerlendiren bir süreçtir. İkincisi eğitim programının akreditasyonudur ve öncelikli olarak eğitim gören kişilerin/öğrencilerin donanımını ve yetkinliğini değerlendiren bir süreçtir. Eğitilenlerin yetkinliği, sadece mesleklerini icra etmek için gereken teknik deneyimi almış olmaları değil, iyi hizmet vermek için gereken etik değerleri ve yeteneği kazanmış olmaları anlamına da gelir. Kısacası eğitim sisteminde akreditasyon, akademik kalitenin iyileştirilmesi, eğitim programının kalite güvencesi altına alınması, şeffaflık ve hesap verebilir olmak anlamına gelmektedir.
\end{abstract}

Akreditasyon sürecinde değerlendirilen başlıklar aşağıdaki şekilde özetlenebilir:[1]

1. Öğrencilere yönelik standartlar.

2. Eğitim ve öğretim amaçlarına yönelik standartlar.

3. Eğitim programının hedefleri.

4. Program çıktıları ve değerlendirmeye yönelik standartlar.

5. Eğitim kadrosunun kalitesine yönelik standartlar.

6. Kurumun eğitimi ilgilendiren altyapısına yönelik standartlar.

Akreditasyon sistemi, eğitimin, eğiticinin ve eğitilenin, tanımlanmış olan yetkinlik ölçütlerini karşılayıp karşılamadığını değerlendirir. Bu ölçütler, eğitimin tüm paydaşları ile ilgili olduğu kadar etik ve özlük hakkı konularındaki düzenlemeleri de kapsar. Böylece, verilen eğitimin kalitesi eğitim programına başvuranların ve aynı zamanda kamuoyunun nezdinde güvence altına alınmış olur. Belli kurumların bulundukları ülkede ve hatta dünyada yaygın olarak bilinen bir ünü olsa da verdikleri eğitimin kalitesini belgelemeleri ancak akreditasyon sürecinden başarı ile çıkmalarıyla mümkündür. Akreditasyon işlemlerinin yapılması için kurum ziyareti programları hazırlanmıştır. Eğitim kurumları akredite olabilmek ve kurum ziyaretine hazırlanmak için faaliyetlerini daha düzenli olarak kaydetmeye, verdikleri eğitim kalitesini daha iyi bir seviyeye çıkarmaya ve belli dönemlerde kendi kendilerini iç denetimden geçirme alışkanlığı kazanmaya başlar (kurumsal öz değerlendirme). Kalite güvencesi sadece belli bir süre geçerlidir ve tek bir defalık yapılan bir işlem değildir. Aksine uzun dönemli ve dönem dönem iç/dış değerlendirmeler ile devam eden bir süreçtir. Kurumun bu süreçlerde tutarlı olması aranan bir özelliktir.

Tıp eğitimi, tıp fakültesine girişle başlayan ve yaşam boyu süren bir eğitimdir. Tıp eğitiminde akreditasyon kavramı, günümüz Türkiye'sinde oldukça yoğun olarak tartışılan bir konudur ve hedefi eğitim kurumlarından yetkin doktorların mezun olmasını sağlamaktır. Tıp eğitiminde gelinen noktada, belli sorunlar ile karşılaşılmaktadır. Teknik bilginin aşırı artması, giderek artan teknoloji bağımlılığı, sağlık alanında metalaşma, sağlık politikaları ile eğitim politikalarının arasında eşgüdümün olmaması, yetersiz altyapı ve sınırlı insan gücü ile açılan yeni tıp fakülteleri ve sonuçta, kurumlar ve eğiticiler arasındaki belirgin farklıııklar oluşması gibi büyük sorunlar ile mücadele etmek gerekmektedir. Bu nedenlerden dolayı, tıp eğitiminde standartların oluşturulması ve bu standartların kurumlarda oluşmasına yardımcı olacak politikaların hayata geçirilmesi gerekmektedir.

- Illetişim adresi: Prof. Dr. Volkan Öztuna, Mersin Üniversitesi Tıp Fakültesi, Ortopedi ve Travmatoloji Anabilim Dalı, 33190 Mersin Tel: 0324 - 3374300 / 1191 e-posta: oztuna67@hotmail.com

- Geliș tarihi: 24 Ekim 2014 Kabul tarihi: 24 Ekim 2014 
Bu açıdan, eğitimci Abraham Flexner'in, 1910 yılında başlayarak ABD ve Kanada'daki 115 tıp fakültesini 18 aylık bir sürede ziyaret ederek kurumlar arası farklılıkları ortaya koyduğu rapor tarihsel önem taşır. Raporda, tıp eğitiminin standartlardan uzak olduğu, eğitim programlarının içeriklerinin belirli olmadığı, ön koşulları taşımayan kurumlar tarafindan verildiği ve önlemlerin alınması gerektiği vurgulanmaktadır. Bu rapor sonrasında tıp fakültelerinin sayısı 30 yıl içinde $155^{\prime}$ ten $66^{\prime} y a$ düşmüş, tıp eğitimi öncesi kolej eğitimi zorunlu hale gelmiş ve tıp eğitiminin ilk iki yılı klinik öncesi temel bilimler, son iki yılı da klinik eğitim olacak şekilde yapılandırılmıştır. Daha sonra Amerikan Tabipler Birliği, belli standartlar tespit ederek, hekimlik yapabilme lisans sınavlarını başlatmıştır. ${ }^{[2]}$

Yetkinlik kavramı ölçülebilir bir değerdir. Fakat kullanılacak olan ölçme ve değerlendirme sistemlerinin geçerliği ve güvenirliği belgelenmelidir. Yetkinlik tanımının ve eğitim sonuçlarını ölçme değerlendirme yöntemlerinin hayata geçmesi 1915 yılına kadar eskilere gitmektedir. O tarihlerde, Amerikan Oftalmoloji Derneği ve Amerikan Tabipler Birliği'nin yayımladığı bir yeterlik sınav duyurusunda, adayların yetkinliklerinin değerlendirileceği bir sınavın planlandığı açıklanmıştır. Takiben 1916 yılında Amerikan Göz Hastalıkları Yeterlik Kurulu kurulmuştur. Bunu 1924 yılında Amerikan Otolaringoloji Yeterlik Kurulu, 1930 yılında Amerikan Kadın Hastalıkları ve Doğum Yeterlik Kurulu izlemiştir. Giderek artan kurulların katılımı ile1970 yılında Amerikan Tıp Uzmanlıkları Yeterlik Kurulu oluşturulmuştur. 1981 yılında ise bu sistemin değerlendirilmesi amacıyla akreditasyon kavramı öne çıkmış ve eğitim veren kurumların hizmet ve eğitim faaliyetlerini değerlendirmek amacıyla bağımsız bir akreditasyon kurumunun olması gerektiğine karar verilmiştir. ABD sınırları içindeki tıp uzmanlık eğitim programlarını (uzmanlık ve yan dal uzmanlığı) değerlendiren ve akreditasyonlarını sağlayan özel bir konsey olarak Mezuniyet Sonrası Tıp Eğitimi Akreditasyon Konseyi (Accreditation Council for Graduate Medical Education - ACGME) kurulmuştur. ${ }^{[3]}$ ABD'deki bu gelişmelere paralel olarak, 90'lı yıllarda Kanada'da The Royal College tarafindan yetkinlik tanımlaması için kullanılan Doktor Yetkinlik Çerçevesi (CanMEDS Physician Competency Framework) yayımlanmıştır. European Union of Medical Specialists (UEMS) ise bu gelişmelerden sonra uzmanlık standartları kılavuzlarını yayımlamaya başlamıştır. Eğitim programlarının akreditasyonu sürecinde gerekli ölçütlerin oluşturulması sırasında da bu temel yetkinlik alanları ve kılavuzlar esas zemini oluşturur.

Akreditasyon sistemi ABD ve Avrupa'da farklı ilkelerle yönetilir. ABD'de eğitim kurumlarının akreditasyonu zorunlu iken Avrupa'da ve ülkemizde gönüllülük esası üzerinden yürütülür. Yani eğitim kurumları, kendi istekleri üzerine yetkili kurumlara başvurarak akreditasyon sürecine katılırlar. Önemli bir diğer unsur ise akreditasyon sürecinin bağımsız ve kurum dışı bir ajans/dernek/ komisyon tarafından yapılmasıdır. Akreditasyon sürecini yöneten ve karara bağlayan yapılanmaların hükümet dışı kurumlar olması, bu sistemin olası siyasi baskılara maruz kalmaması ve verilen kararların günlük politikalar ile değişmemesi açısından önem arz eder. ABD'deki ACGME tamamen sivil ve bağımsız bir yapılanmadır ve bu süreçte "Residency Review Committee" ve "Institutional Review Committee" gibi yapılanmalar aracılığıyla değerlendirme yapar; ulusal standartları belirler, eğitim programlarını onaylar ve sürekli değerlendirir. ${ }^{[4]}$

Türkiye'de ilk defa 1994 yılında Türk Tabipleri Birliği (TTB)'nin önderliğinde gerçekleştirilen I. Tıpta Uzmanlık Eğitimi Kurultayı'nda tıpta uzmanlık eğitimi programları, eğitim kurumlarının altyapıları ve uzmanlığın belgelendirilmesine ilişkin sorunlar ve çözüm önerileri tartışıımıştır. TTB-UDEK (TTB-Uzmanlık Dernekleri Eşgüdüm Kurulu), tıpta uzmanlık eğitiminin en yüksek kalitede ve bilimsel temeller üzerine oturtularak, ülke düzeyinde eşdeğer olarak yapılabilmesi, değerlendirilebilmesi ve denetlenmesini sağlayacak özerk kuruluşlar olan Yeterlik Kurullarının (boards) oluşturulmalarını da hedeflemiştir. TTB-UDEK Ulusal Yeterlik Kurulunun (UYEK) çalışmalarının başlaması ile genel olarak o güne kadar dağınık ve kendi içine kapalı bir yapılanma gösteren uzmanlık dernekleri arasında hem bir deneyim aktarımı olmuş hem de derneklerin otokontrol süreçleri harekete geçmiştir. Böylece, uzmanlık dernekleri yeterlik kurulları eğitim programlarının hazırlanması ve bunların uzmanlık öğrencileri tarafından takip edilmesini sağlayan "öğrenci karneleri", eğitim kurumlarının yeterli altyapı ve insan gücü olanaklarını değerlendiren "akreditasyon" işlemi ve uzmanlık öğrencilerinin eğitimleri sonunda aldıkları bilgi ve uygulamanın ölçülebilmesini sağlayan "yeterlik sınavları" üzerine çalışmalar başlatmıştır.

TTB-UDEK tarafindan, 2011 yilında "Tıpta Uzmanlık Eğitiminde Ulusal Standartlar” başlığı ile bütün uzmanlık alanlarını kapsayacak temel ilkeler belirlenmiştir. ${ }^{[5]}$ Türkiye'deki tüm yeterlik kurulları bu genel tanımlamalardan esinlenerek kendi alanlarına uygun ayrıntılı ölçütleri oluşturmaya başlamıştır: Uzmanlık eğitimi verilen kurumlarda, eğitimin farklı aşamaları ve asistan hekimin (tıpta uzmanlık öğrencisi / araştırma görevlisi) etkinlikleri bir asistan karnesine kaydedilmeli ve her bir asistan hekim için yapılandırılmış bir eğitim programı bulunmalıdır. Süreç içerisinde bir süre kurumu ziyarete hazır hale getirmekle uğraşılır. Kurumun eğitim programları, yapısı, yayınları, çalışmaları hepsi incelenir. Birimin bir yılda yaptığı poliklinik, yatırdığı 


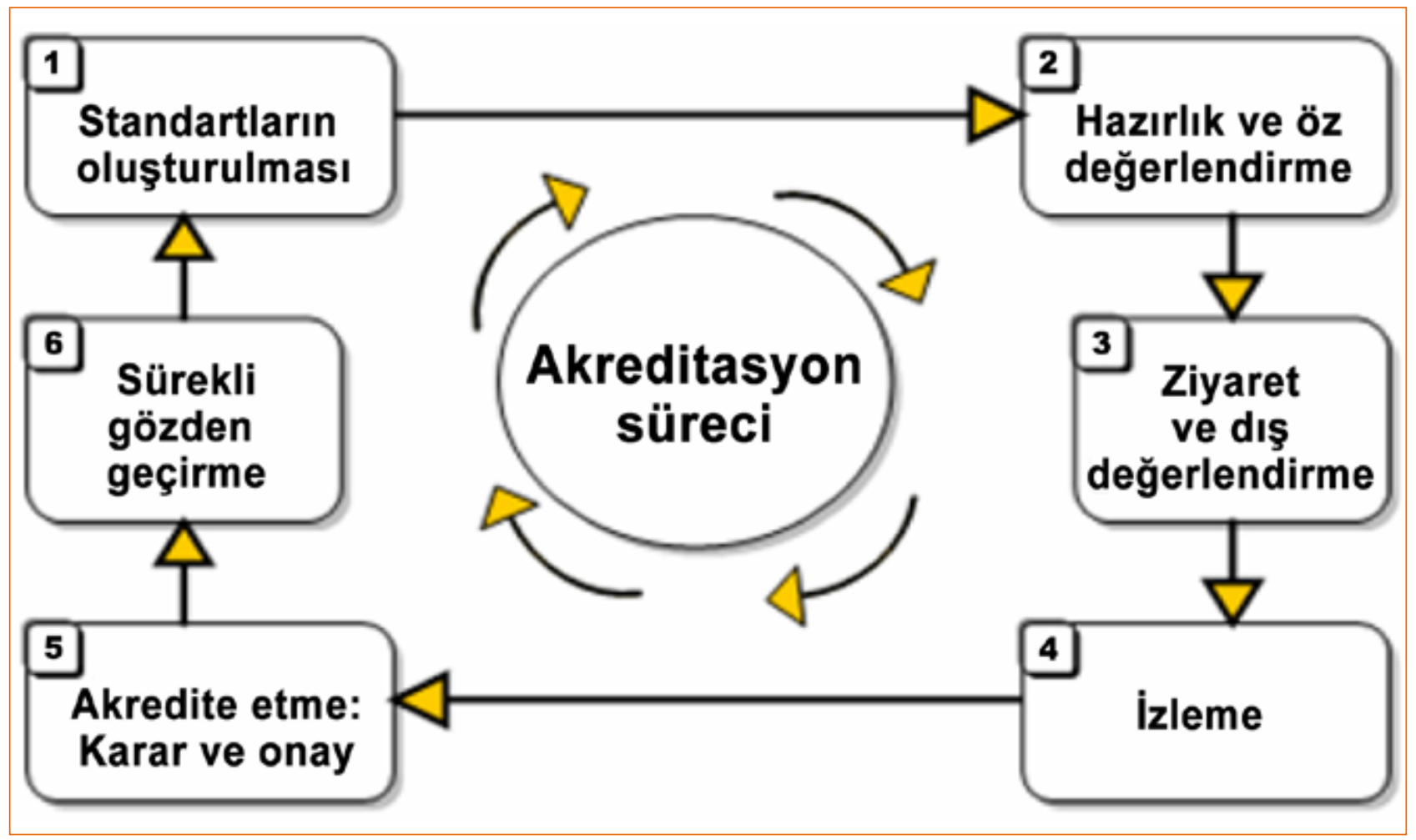

Şekil 1. Akreditasyon süreci ve yapılacak işlemler. ${ }^{[1]}$

hasta sayıları, yaptıkları ameliyat ve girişimler, konsültasyonlar, aciller, düzgün kayıt sistemi olup olmaması değerlendirilir.

Kurulduğu tarihten itibaren uzmanlık eğitiminin akreditasyonu için program hazırlayan TOTEK'in bu yoğun çalışmaları sonunda, 6 . dönem TOTEK-YK tarafından kurum ziyaretleri programı başlatılmıştır. Gönüllü olarak bu programa başvuran kliniklere yapılan ziyaretler sonucunda "EK 5.Türk Ortopedive Travmatoloji Eğitim Konseyi (TOTEK) Kurum Ziyaretleri ve Akreditasyon Programı Esasları ve Akreditasyon Standartları"nı karşılayan; İstanbul Üniversitesi, İstanbul Tıp Fakültesi Ortopedi ve Travmatoloji Anabilim Dalı (ziyaret tarihi, 18 Temmuz 2012), “GATA” Askeri Tıp Fakültesi Ortopedi ve Travmatoloji Anabilim Dalı (ziyaret tarihi, 28 Mart 2013), S.B. Metin Sabancı Baltalimanı Kemik Hastalıkları Eğitim ve Araştırma Hastanesi Ortopedi ve Travmatoloji Kliniği (ziyaret tarihi, 9 Temmuz 2013) ve İzmir Tepecik Eğitim ve Araştırma Hastanesi Ortopedi ve Travmatoloji Kliniği (ziyaret tarihi, 9 Ekim 2013) tarafından verilen uzmanlık eğitimleri beş yıl süreyle geçerli olmak üzere akredite edilmiştir.

Yeterlik Kurulları, eğitim kurumlarını ziyaret programlarına katılmaya cesaretlendirmelidir. Akreditasyon süreci (Şekil 1) eğer olumlu olarak sonuçlanırsa kurumun yetkinlik ölçütlerine sahip olduğu gösteren bir belge düzenlenir. Belgelendirmeye uygun bulunmayan kurumlara ise düzeltilmesi, geliştirilmesi gereken eksikleri bildirilir ve yeni bir ziyaret tarihi belirlenir. ${ }^{[6]}$ Kurumun standartların üzerine çıkmış olan özellikleri varsa bu durumlar özellikle belirtilerek kalitenin yükseltilmesi için bir cazibe ve itici güç oluşturmaya çalışılmalıdır.

\section{KAYNAKLAR}

1. Aktan CC, Gencel U. "Yüksek Öğretimde Akreditasyon". İçinde: Aktan CC, editör. Değişim Çağında Yüksek Öğretim, İzmir: Yaşar Üniversitesi Yayını; 2007.

2. Beck AH. STUDENTJAMA. The Flexner report and the standardization of American medical education. JAMA 2004;291(17):2139-40.

3. http://www.acgme.org/acgmeweb/

4. Kimatian SJ. Postgraduate medical education: how do we know it's working? Anesth Analg 2006; 102(1):209-12.

5. Sayek I, Batı H, editörler. Tıpta Uzmanlık Eğitimi Ulusal Standartları. Ankara: Türk Tabipleri Birliği Yayınları; 2011.

6. Özgür F. TTB-UDEK/ Ulusal Yeterlik Kurulu 2010-2012 Döneminde Kurum Ziyaretleri Nasıl Devam Etti? TTB-UDEK Bülteni 2012;7:29-34. 